\title{
A STUDY ON THE MEASUREMENT OF SYSTEMATIC RISK IN \\ CHINA 'S SECURITIES INDUSTRY
}

\author{
Xiaojing Guo \\ Shanghai University, P.R. China
}

\begin{abstract}
This paper calculates the risk spillover effect of China's securities companies based on the GARCH CoVaR model, and makes an empirical analysis on the contribution of 10 listed securities companies to the systemic risk of the securities industry. The study shows that the size of the risk spillover \% CoVaR is not related to the $\mathrm{VaR}$, and the risk spill value reflects the contribution degree to the systemic risk. The risk of the securities company with small VaR is small, but it cannot explain how it contributes to the systemic risk. Through the research of this paper, we hope to attract scholars' attention to CoVaR and risk spillover effect. As a new macro-systemic risk control tool, CoVaR is a useful complement to the traditional VaR model and will become a new kind of choice to the financial regulators .
\end{abstract}

Key words: GARCH model, CoVaR, Systemic risk, VaR

JEL code:M0， M1

\section{Introduction}

\subsection{Research Background}

Refers to the risk of a single broker, the risk spillover effect between the securities traders, will not only bring their own losses, but also transmit to other brokers, and even the entire securities system, which have triggered "domino effect" and brought huge catastrophic consequences to the entire securities industry. The outbreak of the subprime crisis in 2007 was triggered by a single agency and spread rapidly to the entire financial system, leading to a global financial crisis. It can be said that the outbreak of the global financial crisis once again raised the world's attention to the issue of financial risk management and regulatory, especially for the regulatory aspects of systemic risk.

The vast majority of economists will focus on research on the banking sector, because the systemic risk of commercial banks has a strong contagious, once the outbreak will cause huge losses. But we should also see the securities industry has always been a high-risk industry, although the financial crisis did not affect China's securities industry, but with the gradual increase in the degree of openness of our securities companies, business scope continues to 
expand, derivative financial products more and more the more the vulnerability of securities companies is gradually emerging, so it is necessary to study the systemic risk of China's securities industry.

\subsection{Research Significance}

China's securities industry from scratch to achieve rapid development is only nearly three decades of things, along with the economic system and financial market reform and development, after years of comprehensive management, securities have gradually developed into China's financial system and even the important national economy component. Although the scale of the securities industry in China's financial system is still not too large, but with the financial institutions between the gradual increase in the relationship between financial risk and infectious, the systemic risk of the securities industry is still very important.

Taking China's securities industry as an example, this paper is based on this consideration, using CoVaR method to measure the systemic risk of China's securities industry as well as the spillover effects of various securities companies on systemic risk of the industry, and to provide suggestions for the systematic risk control and supervision of the securities industry.

\subsection{Literature Review}

the US subprime mortgage crisis and the European debt crisis swept the world, which has brought serious impact to the world economy, many domestic and foreign research institutions and senior scholars have carried out a very professional qualitative and quantitative research, but also made a lot of meaningful research Results. There are many empirical studies based on CoVaR method. The empirical research on this method is mainly focused on the systematic risk measurement of China's banking industry. The following mainly on the systematic risk measurement methods of domestic and foreign literature are to sort out and review.

Since the outbreak of the financial crisis, many foreign scholars on the systemic financial risk of a more comprehensive and in-depth analysis. Adrian and Brunnermeie (2008), based on the market data, proposed a conditional VaR method based on the VaR method of mainstream risk management technology to measure the size of systemic financial risk. CoVaR is intended to measure the risk spillover effects on other institutions when a mechanism is in crisis. This risk spillover effect may come from a direct risk spillover effect or an indirect risk spillover effect. Huang et al. (2009) constructed disaster insurance indicators to measure the contingency expectations of loss of financial systems under extreme conditions and used marginal contribution rate indicators to measure the contribution of individual banks or individual banking groups to systemic financial risks. Drakos and Kouretas (2011) used the emerging markets economies in Latin America, Central and Eastern Europe and South Asia as the object of study, using the CoVaR model to establish the CoVaR model from the years of the year to the year, to estimate the financial system banking, insurance and financial services Contribution of Sector to Systematic Risk of Financial Market. 
There are many scholars in China that use CoVaR to measure the risk spillover effect of China's banking industry. This includes two methods: calculating VaR by using the quantile regression method and calculating the VaR by using the GARCH model to calculate the volatility.

Xie (2010) uses the quantile regression technique combined with the conditional risk value method CoVaR for empirical research. The results show that the direction and size of the risk spillover effect between China's stock market and bond market are different. Fan (2011) used the latest CoVaR method and the quantile regression technique to calculate the systematic risk premium of China's commercial banks. The study found that the systemic risk premium of state-owned banks is greater than that of joint-stock commercial banks, and the existing regulatory policies with $\mathrm{VaR}$ as the core indicators cannot effectively prevent the systemic risk premium. $\mathrm{Li}$ (2012) also uses the method of quantile regression to calculate the risk spillover value of commercial banks in China. It is believed that the banks with strong competitiveness in the regional market are stronger than those in the banking industry. Part of the national commercial banks, while the assets of large banks on the overall risk of banking spillover effect. Guo (2013) uses the CoVaR method and the quantile regression technique to calculate the systemic risk value and risk spillover value of 14 listed banks in China. It is considered that the large-scale banks have a greater risk of systemic risk spillovers. The greater the contribution coefficient, the greater the negative externalities. On the contrary, the negative externalities of small banks are small.

Some scholars have used the GARCH model to fit CoVaR. Li et al. (2009) used the ARMA-GARCH model to accurately calculate the VaR and CoVaR values, and the two values increase as the given probability $\mathrm{p}$ decreases. Based on the AR-GARCH-CoVaR model, this paper makes an empirical study on the systematic risk spillover effect of three listed insurance companies in China. Gao and Pan (2011) used the GARCH-CoVaR model to analyze the relationship between the degree of systemic risk contribution and the financial characteristics and macroeconomic fluctuation of China's listed banks. It was concluded that the degree of banking system risk and its own VaR had no significant linear relationship.

\section{Systemic Risk and Its Metrics}

\subsection{VaR Value at Risk}

$\mathrm{VaR}$ is the maximum loss that a financial institution or portfolio may suffer in a given period of time at a given level of confidence during a given period of holding. The mathematical expression is:

$$
\operatorname{Pr} o b(\Delta p<-V a R)=1-\alpha
$$

Prob is the probability, $\alpha$ is a confidence level. The method was proposed by JP Morgan in the 1990s and has become the mainstream technology used in the field of risk management.

The mathematical expression of $\mathrm{VaR}$ is: 


$$
V a R_{i t}=\hat{R}_{i t}-Q(q) \hat{\sigma}_{i t}
$$

$R_{i t}$ is the one-step forward forecast for the selected GARCH model. $\sigma_{i t}$ is the square root (standard deviation) of the forward predictor conditional variance. $\mathrm{Q}(\mathrm{q})$ is the quantile at $\mathrm{q}$ significance level. Therefore, the t-quantile and the mean and conditional variance obtained by the GARCH model are the indispensable element in the calculation of VaR.

\subsection{CoVaR}

CoVaR represents the maximum potential loss of other institutions or portfolios in the next period of time when the financial institution or portfolio is lost to $\mathrm{VaR}$ at a given time in a given period of time and at a certain level of confidence. Therefore, when the loss of brokerage $\mathrm{j}$ is $\mathrm{VaR}$, the maximum possible loss of broker $\mathrm{i}$ can be expressed as:

$$
\operatorname{Pr} \operatorname{ob}\left(X^{i} \leq \operatorname{CoVaR}_{q}^{i, j} \mid X^{j}=\operatorname{VaR}_{q}{ }^{j}\right)=q
$$

$\operatorname{Prob}(\bullet)$ Represents the probability, $\mathrm{X}$ represents the risk loss, and 1-q is the confidence level The mathematical expression of CoVaR is

$$
\operatorname{CoVaR}=\hat{R}_{i t}-Q(q) \hat{\sigma}_{i t}
$$

Same as before, is the one-step forward forecast for the selected GARCH model. $\sigma_{i t}$ is the square root (standard deviation) of the forward predictor conditional variance. $Q$ (q) is the quantile at q significance level.

\subsection{The Measure of Risk Spillover}

Define the risk spill value of broker i to broker $\mathrm{j}$, its mathematical expression is:

$$
\Delta \operatorname{CoVaR}_{q}^{i, j}=\operatorname{CoVaR}_{q}^{i, j}-\operatorname{VaR}_{q}^{i}
$$

We can see that the risk added value of the broker $i$ is the difference between the value of bank $\mathrm{j}$ on bank i's conditional risk and the unconditional value of its own. This is the absolute magnitude of the risk spill.

For the sake of comparison, we generally also calculate the relative magnitude of the risk spillover value. The formula for the proportion of brokerage $\mathrm{j}$ to the risk of brokerage $\mathrm{i}$ is:

$$
\% \operatorname{CoVaR}{ }_{q}^{i, j}=\Delta \operatorname{CoVaR}{ }_{q}^{i, j} / \operatorname{VaR}_{q}^{i}
$$

It can be seen that the calculation of the risk spillover value needs to calculate the VaR and the conditional risk value CoVaR. Considering the time variability, asymmetry and agglomeration of financial data, this paper will use GARCH-VaR model and GARCH-CoVaR model to calculate the VaR and VaR respectively. 


\section{An Empirical Study on Systematic Risks}

\subsection{Research Sample}

Combined with previous research, and because of the representation and availability of data, this paper selected listed securities companies as a research object. As part of the securities companies listed late, and part of securities companies are at a suspended state in a certain period of time, so they have to be removed. The securities companies selected in this article are listed on October 15, 2010, the transaction time has been more than four years. The transaction data is sufficient analysis, and very representative. Therefore, this article selected the 10 securities companies as research samples.

The ten securities companies are: GuangDa Securities, GuangFa Securities, Huatai Securities, Industrial Securities, CITIC Securities, State Securities, China Merchants Securities, Southwest Securities, Haitong Securities, the Pacific Securities.

\subsection{Data Selection and Processing}

The empirical part of this article selected the stock Closing price and brokerage index as the basic research data of the 10 securities companies, the time zone is from the January 6, 2012 to December 30, 2016 every Friday (such as Friday is a holiday or other special circumstances, using the previous day's trading data), and select the same period of the Shanghai Composite Index, a total of 255 weeks of data.

For research convenience, we need to each securities company stock closing price and brokerage index and other data processing, and get the corresponding rate of return or rate of return. We have to take the logarithmic first order difference for each week to calculate the weekly yield, the formula is expressed as:

$$
R_{t}=100 * \ln (\mathrm{t} \text {-week closing price or price index / t-1 week closing price or price index) }
$$

In order to ensure the reliability of the data, the securities used in the text of the stock closing price, the Shanghai index, brokerage index and other data are all from the wind information and flush software, using Eviews8.0 software to deal with the above data and the establishment of models, respectively, calculate the risk spillover effect of 10 securities companies on the entire securities industry.

\subsection{Empirical Research and Analysis}

First of all, according to the above formula, calculate the stock price of each securities company.

GD represented GuangDa Securities, GF represented GuangFa Securities, GJ represented State Securities, HAITONG represented Haitong Securities, HT represented Huatai Securities, TPY represented Pacific Securities, XN represented Southwest Securities, XY represented 
Industrial Securities, ZS represented Merchants Securities, ZX represented CITIC Securities. From the figure, we can see that the ten securities companies have basically a similar rate of return, and, of which the rate of return volatility of GF, GD is relatively large.

Secondly, securities company stock price rate chart can only reflect the basic trend of data, in order to describe stock closing price and brokerage index and other data better, we can calculate the securities companies by the stock price and brokerage index yield rate of the mean, skewness and kurtosis of the three statistical variables to further analysis of these data. The formula is:

$$
\begin{gathered}
S=\frac{1}{n} \sum_{i=1}^{n}\left(R_{i}-\frac{\bar{R}}{\sigma}\right)^{3} \\
K=\frac{1}{n} \sum_{i=1}^{n}\left(R_{i}-\frac{\bar{R}}{\sigma}\right)^{4} \\
J-B=\frac{n-m}{6}\left[S^{2}+\frac{1}{4}(K-3)^{2}\right]
\end{gathered}
$$

Where $\mathrm{S}$ is skewed and examined the degree of asymmetry of the distribution of the sample. If $S<0$, the data distribution is left-handed and vice versa; $K$ is the kurtosis, examine the degree of concentration of the test variables and the steepness of the distribution curve. If $\mathrm{K}>$ 0 , then the data is more concentrated than the normal distribution in the vicinity of the mean. The larger the $\mathrm{K}$ is, the more the variable distribution curve is. The Jarque-Bera statistic is also used to test the normality of the variable distribution. The larger the J-B value is, the more it indicates the variable distribution deviates from the normal distribution. Calculate the above three statistics.

The results of the calculation of the weekly yield data of several other securities companies are shown in Table 1.

Table 1 Statistical analysis of the stock returns of each securities company

\begin{tabular}{cccccc}
\hline Stock name & Rate of return & Mean & Skewness & Kurtosis & J-B value \\
\hline GD Securities & $R^{\text {gd }}$ & 0.1841 & 0.6661 & 7.4807 & 232.1684 \\
\hline GF Securities & $R^{g f}$ & -0.0781 & -2.8342 & 33.5646 & 10267.19 \\
\hline HT Securities & $R^{\text {ht }}$ & 0.3471 & 1.0610 & 8.0956 & 323.7229 \\
\hline Industrial Securities & $R^{\text {xy }}$ & -0.0907 & -2.4894 & 28.0716 & 6942.116 \\
\hline CITIC Securities & $R^{z x}$ & 0.2105 & 0.7967 & 6.8187 & 181.9182 \\
\hline State Securities & $R^{g j}$ & 0.1157 & -2.5203 & 24.0204 & 4964.486 \\
\hline Merchants Securities & $R^{z s}$ & 0.1869 & 1.2706 & 9.8971 & 574.0465 \\
\hline Southwest Securities & $R^{x n}$ & -0.0821 & -2.4086 & 39.0792 & 14077.20 \\
\hline Haitong Securities & $R^{\text {haitong }}$ & 0.3016 & 0.1834 & 5.0228 & 44.9058 \\
\hline Pacific Securities & $R^{\text {tpy }}$ & -0.1096 & -1.0029 & 11.7725 & 860.4062 \\
\hline Brokerage index & $R^{q s}$ & 0.2934 & -0.8760 & 6.6982 & 177.9254 \\
\hline
\end{tabular}


From Table 1 we can see that most of the securities companies' stock returns and brokerage index yields show left partial state, the securities companies stock yield series kurtosis is greater than 3, the tail of the sequence distribution is thicker than the normal distribution. The distributions of all yield sequences show the characteristics of "posterior peak, asymmetric distribution". The p value of the J-B statistic is 0 , which is consistent with most financial events. sequence.

Thirdly, using the ADF test method, the stability of 10 listed securities companies' stock returns and the stability of the brokerage index yield were tested. The test results are shown in Table 2.

Table 2 ADF test results of stock returns for each securities company

\begin{tabular}{ccccc}
\hline Stock name & Rate of return & ADF value & \%5Critical value & P value \\
\hline GD Securities & $R^{\text {gd }}$ & -14.9392 & -2.8727 & 0.0000 \\
\hline GF Securities & $R^{g f}$ & -15.4636 & -2.8727 & 0.0000 \\
\hline HT Securities & $R^{\text {ht }}$ & -14.9254 & -2.8727 & 0.0000 \\
\hline Industrial Securities & $R^{\text {xy }}$ & -15.1700 & -2.8727 & 0.0000 \\
\hline CITIC Securities & $R^{z x}$ & -14.3218 & -2.8727 & 0.0000 \\
\hline State Securities & $R^{g j}$ & -15.7130 & -2.8727 & 0.0000 \\
\hline Merchants Securities & $R^{z s}$ & -14.2991 & -2.8727 & 0.0000 \\
\hline Southwest Securities & $R^{x n}$ & -16.5428 & -2.8727 & 0.0000 \\
\hline Haitong Securities & $R^{\text {haitong }}$ & -15.1656 & -2.8727 & 0.0000 \\
\hline Pacific Securities & $R^{\text {tpy }}$ & -15.2436 & -2.8727 & 0.0000 \\
\hline Brokerage index & $R^{q s}$ & -15.0762 & -2.8727 & 0.0000 \\
\hline
\end{tabular}

The test results show that the stock returns rate of each securities firm is a stationary sequence at $95 \%$ confidence level, and it has the prerequisite for establishing the GARCH model. Therefore, we can calculate the $\mathrm{VaR}$ and CoVaR values of the securities companies by establishing the GARCH model.

Forth, to process the stock price of the securities companies and brokerage index yield data. The results of previous studies show that the quantile regression method cannot describe the nonlinear structure between sequences and may underestimate the correlation between sequences. Therefore, we need to establish AR (1) -GARCH $(1,1)$ model and ARMA $(1,1)$ -GARCH $(1,1)$ model, and then calculate the VaR and CoVaR of each securities firm when the confidence is $95 \%$ value.

The clustering of financial data is the main reason we choose to use GARCH model, which can be visualized in a graph. Take GuangDa Securities as an example, perform an ARCH test on the yield sequence. A single regression equation is established by CAPM model, and its residuals are analyzed. The specific regression model is as follows:

$$
R^{g d}=\beta_{0}+\beta_{1} R^{s z}+\varepsilon_{t}
$$


Where $R^{g d}$ is the logarithmic yield of GuangDa Securities, $R^{s z}$ is the logarithmic yield of the market and is replaced by the logarithmic yield of the Shanghai Composite Index, $\varepsilon_{t}$ is the residual term. The ARCH LM test was performed on the data, and the results of the ARCH LM test with the lag order of 1 were obtained. As shown in Table 3:

Table 3 ARCH LM test results

\begin{tabular}{clll}
\hline F statistic & 37.5494 & Probability value $(\mathrm{p})$ & 0.0000 \\
\hline$T \times R^{2}$ statistic & 32.9393 & Probability value $(\mathrm{p})$ & 0.0000 \\
\hline
\end{tabular}

As can be seen from Table 3, the p-values of the two statistics are well below 0.01, indicating that the residual sequence has an ARCH effect, so select the GARCH model to estimate the VaR value is correct. Similarly, the other securities companies can verify the yield data.

Ultimately, consolidate the calculation results of the risk spillover value of each securities company. According to the calculation method of GARCH-CoVaR, the risk overflow value \% CoVaR sequence of all banks is calculated. The first step, select the appropriate GARCH model of the securities companies to rate the data to fit ; The second step is to calculate the VaR sequence of a single securities firm based on the fitting mean and conditional variance results ;In the third step, the yield of the brokerage index is fitted with the VaR sequence of the single securities company to establish the GARCH model ; In the fourth step, the CoVaR sequence is calculated from the fitted mean and conditional variance results ;finally, In order to obtain the contribution degree of the securities company to the systemic risk of the securities industry, the result of the risk spillovers \%CoVaR is calculated according to the calculated results of the CoVaR sequence. Table 3-4 lists the results of the risk spillover values for all securities companies. To prevent some extreme values from influencing the results, we did not use the median to compare the results. The end result is as follows:

Table 4 Risk value and risk spillover value of each securities company

\begin{tabular}{ccccc}
\hline Stock name & VaR value & CoVaR value & \%CoVaR value & $\Delta$ CoVaR value \\
\hline GD Securities & -7.37 & -7.29 & 0.77 & 0.88 \\
\hline GF Securities & -15.01 & -10.48 & 4.05 & 0.77 \\
\hline HT Securities & -10.04 & -5.67 & 3.63 & 0.61 \\
\hline Industrial Securities & -8.38 & -11.91 & -3.41 & 1.39 \\
\hline CITIC Securities & -7.26 & -5.47 & 1.63 & 0.75 \\
\hline State Securities & -15.82 & -25.44 & 4.78 & -19.98 \\
\hline Merchants Securities & -8.17 & -7.42 & 1.47 & -2.41 \\
\hline Southwest Securities & -14.47 & -15.01 & 3.03 & -9.81 \\
\hline Haitong Securities & -9.05 & -5.99 & 1.11 & -0.87 \\
\hline Pacific Securities & -473.70 & -7.53 & 1.38 & -2.63 \\
\hline
\end{tabular}

For the sake of simpler comparison, this paper sorts the VaR and the conditional risk value 
CoVaR of the securities companies in the descending order. The results are shown in Table 5.

Table 5 Ranking of risk value and risk spill value of each securities company

\begin{tabular}{cccccc}
\hline Stock name & VaR value & Ranking order & CoVaR value & Ranking order & change \\
\hline Pacific Securities & -473.7 & 1 & -7.53 & 5 & decline by 4 \\
\hline State Securities & -15.82 & 2 & -25.44 & 1 & rise by 1 \\
\hline GF Securities & -15.01 & 3 & -10.48 & 4 & decline by 1 \\
\hline Southwest Securities & -14.47 & 4 & -15.01 & 2 & rise by 2 \\
\hline HT Securities & -10.04 & 5 & -5.67 & 9 & decline by 4 \\
\hline Haitong Securities & -9.05 & 6 & -5.99 & 8 & decline by 2 \\
\hline Industrial Securities & -8.38 & 7 & -11.91 & 3 & rise by 4 \\
\hline Merchants Securities & -8.17 & 8 & -7.42 & 6 & rise by 2 \\
\hline GD Securities & -7.37 & 9 & -7.29 & 7 & rise by 2 \\
\hline CITIC Securities & -7.26 & 10 & -5.47 & 10 & constant \\
\hline
\end{tabular}

From the results table, we can get some of the following conclusions:

(1) On the choice of the estimation model

In the calculation of the VaR of the securities companies, we draw the symmetric GARCH model to estimate the AR (1) -GARCH $(1,1)$ model by drawing on the previous research results. In addition, adding the autoregressive term will slightly increase the model's goodness of fit.

In the calculation of the CoVaR values of the securities companies, if the asymmetric GARCH model is used, the coefficients before the reaction asymmetry are not significant, so the symmetrical GARCH model is used to fit the effect better. This may be because the brokerage index includes more than 10 listed securities companies, thus eliminating the asymmetry. In addition, the autoregressive and moving averages are added in the process of model fitting, and the autoregressive and moving averages are added and the degree of fitting of the model is improved.

(2) On the Relationship between VaR and Risk Overflow \%CoVaR

The empirical results show that the VaR values of the 10 securities companies selected in this paper are large (3\% are the limit of comparison). The main reason is that these 10 securities companies are in a systematic and important position in the securities industry and have more many business or financial aspects of the association.

In order to more easily see the relationship between VaR and \%CoVaR, we sorted the two columns of data, from the results table, it can be found that there is no obvious link between them. After the introduction of CoVaR value, the ranking of the securities companies changed in different degree. After in the introduction of CoVaR, CITIC Securities' ranking order has not changed; State Securities, Southwest Securities, Industrial Securities, Merchants Securities, GuangDa Securities rankings have increased, especially Industrial Securities rose 4, the degree of increase is relatively large. This shows that some securities companies 
themselves are at low risk, but the impact of the entire securities industry system is large, and some securities companies are just the opposite. Not only its own risk is greater, the impact of the entire securities industry system is also great. Therefore, regulators need to choose the appropriate management approach to focus on their control, to ensure the stability of the securities industry. On the other hand, this also proves the limitations of traditional VaR methods. This is why, the CoVaR method, which takes into account the risk spillover utility, is a better choice for VaR in risk regulation of financial regulators.

\section{The Conclusion}

This paper makes an empirical study on the contribution of 10 securities companies to systemic risk, and finds that the overall systemic risk of China's securities industry is smaller than that of banking industry. Moreover, the listed securities companies on the entire securities industry relative risk spill a greater degree of difference. There is no obvious relationship between the size of the risk spill and the VaR value. It is illustrated that some securities companies themselves are at low risk, but the impact of the entire securities industry system is large, and some securities companies are just the opposite. And the \%CoVaR value is also no obvious regularity.

Therefore, it is of practical significance that CoVaR as a kind of improvement of VaR. The latter can only measure the risk of each financial institution itself, but cannot measure the risk transfer between the various brokerage agencies, especially in the event of a serious financial crisis. As a regulatory tool for systemic risk, CoVaR is a very necessary complement to VaR, especially in today's increasingly important emphasis on systemic risk regulation. CoVaR transforms the risk spillover effect into a specific number with strong operationality. Financial institutions and regulators can use CoVaR to assess the extent of the impact of financial institutions on the spillover effects of other financial institutions and improve the accuracy of making decision risk.

For the monitoring of the systemic risk of China's securities industry, we should start from the three aspects of internal risk early warning, internal risk monitoring and external risk monitoring. Only internal and external risk monitoring can effectively prevent systemic risk on China's financial market and make the great impact to the real economy. 


\section{References}

Anastassios, A. Drakos, Georgios P. Kouretas. (2015) "Bank ownership, financial segments and the measurement of systemic risk: An application of CoVaR", International Review of Economics \& Finance, pp. 127-140.

Dai, S., Luo, X. and Shen, Y., (2014) "Study on systemic risk spillover effect of China's financial industry - based on GARCH-Copula-CoVaR model", Contemporary Economic Science, pp. 30-38.

Fan, X., Wang, D. and Fang, Y. (2011) "Study on the Measurement and Regulation of the Systematic Risk Contribution of China's Financial Institutions - Based on Marginal Risk Contribution and Leverage Rate", Nan Economic Research, vol. 04, pp. 3-20.

Guo, W. (2013) "Systematic risk value and spillover of Chinese listed banks - Empirical analysis based on CoVaR method", Journal of Beijing Technology and Business University (Social Science Edition).

Gao, G. and Pan, Y. (2011) "Bank systemic risk measurement - based on dynamic CoVaR method analysis", Journal of Shanghai Jiao tong University, vol. 12, pp. 1753-1759.

Huang, J. (2015) "CoVaR based on the real estate industry on the banking risk spillover effect”, Southeast University.

Li, Z. and Fan, L. (2011) "Empirical Study on Systematic Risk Premium of Chinese Commercial Banks", Contemporary Economic Science, vol. 06, pp. 13-20.

Mao, Y. and Wang, L. (2010) "Study on Financial Systematic Risk and Macro-Prudential Supervision”, International Finance Research, vol. 08, pp. 59-68.

Shi, Y., Ding, W. and Yuan, S. (2013) "Market interconnection, risk spillover and financial stability - based on the stock market and bond market spillover effect analysis", Finance Research, vol. 03, pp. 170-180.

Tao, L. and Zhu, Y. (2016) "Systematic financial risk monitoring and measurement - based on China's financial system research", Finance Research, pp. 18-36.

Wang, R. (2016) "Bidirectional spillover effect of financial system risk and its CoVaR model estimation”, Statistics and Decision, vol. 02, pp. 146-148.

Xie, F. (2011) "Study on risk spillover measure of Chinese and foreign stock market based on GARCH-Copula-CoVaR model”, Guangdong Business College.

Zhao, J., Zhang, S. and Wei, W. (2013) "Comparison and Application of Systematic Financial Risk Measurement Method”, Research in Statistics, vol. 10, pp. 46-53. 